him a plentiful supply (3 pints) of new milk with Liebig's extract of meat in sufficient quantity to disguise the milk. This he took for a considerable time, but no meat or other diet. I also gave him peppermint water to make him think he was taking medicine. After three or four weeks he got tired of the disguised milk, and I told him that as soon as he would take the ordinary food he should give it up gradually in proportion as he took meat. This was gradually done, and he soon regained the ordinary habits of living and got rid of his foolish idea of liver disesse, and remained quite well.

CASE III-A sister of the last case, aged about 13 years. A healthy looking girl. I was consalted about her for a supposed disease of the kidney. The friend accompanying her brought me some urine heavily laden with a yellowish precipitate resembling lithates, which was partially soluble in nitric acid, with slight effervescence. From the first I strongly suspected fraud, but as she had been under the care of another practitioner I exercised caution; but in a short time I felt sure she was trying to deceive me. Having gained the confidence of her governess, I told her my suspicions, instructing her to send me by post two specimens of arine-one passed under her supervision and kept by her, the other passed by the girl and left under her own care. I instructed the governess not to tell the mother of my suspicions. Then the fraud became clear. I received the two specimens. No. I perfectly normal; No. 2 "treated" by the girl herself, laden with deposit. I then requested the mother to bring the girl herself, with a specimen of the urine passed and dealt with by the girl herself, which presented the same appearance as that referred to as No. 2. Having made an excuse for sending the girl out of the room, I told the mother what I sus. pected. Of course she was very much annoyed, but I reasoned with her, and showed her the importance from a moral point of view, and requested to be left alone with the girl, when I kindly but forcibly challenged her as to fraud. At first she denied, but I persisted, and telling her if she told me the trath she should not be punished, and pointing out the evil of her conduct, and convincing her that I knew the trick, she confessed that she was in the habit of scraping the wall of her room, and putting the powder in the urine. Nothing bat full determination on my part would havesolved the mystery. The motives influencing the brother and sister are very diff calt to explain or understand, there being apparently nothing to be gained by their conduct, unless a morbid desire to create or excite sympathy, with a perverted moral sense, be accounted sufficient explanation for such extraordinary conduct.

CASE IV. - The next osse is evidently one of decided imposition for the purpose of gaining sympathy and extort. ing charity, and imposed for a long time on several persons who visited the woman. A delicate-looking woman, subject to a chronic cough, commenced spitting a coloured fluid, representing that she coughed it up. For a time I was deceived, but fortunately I detected some fine filaments of a pink appearance, and on carefal examination these were found to be small bits of pink cotton, cat up very finely, which bad been chewed, and the coloured saliva was then expectorated as blood!

CASE v.-Some years since, when surgeon to the Children's Hospital in this city, a practitioner told me of a curious case, and said be would like me to seo it in consultation, and it was partially arranged, but not carried out. He told me the child, aged about 12 yeare, was unable to walk or stand. From his description I sug. gested it was a case of hysteria. I did not then see the child, but understood that her mother had taken her to see a "specialist" in London (unfortunately, I believe, without any letter of explanation from her medical attendent), who, doubtless gaided only by the statements of the mother, probably not quite accurate, gave the opinion that she was suffering from some spinal affection, and ordered perfect rest in a special apparatus, to prevent motion. After some months, as no benefit was derived, I was asked to take the child into the hospital, and did so. On the day after admission I spoke to the child, and taking her little hands in mine, gently raised her into a sitting position, although she positively asserted that she could not sit up. I then got her round, still sitting, and taking down the side of the cot, got her to let her legs dangle for a few minutes. Next day I got her to stand on the flnor, still holding her, and the following day got her holding the rails of the cot (one on either side) to walk a few paces. The next day she made further progrese, and on the fourth day she walked, assisted by the nurse and myself, across the ward; on the fifth day she walked a short distance alone, and the following week she was discharged quite well.

I presume it has frequently fallen to the lot of practitioners to meet with cases of strong robust men, in whom not a shadow of pretence could be traced, who after long confinement to bed, have felt quite unable to stand. One such occurs to my mind. A strong healthy farmer, energetic and active, was sufforing from a painful attack of gouty lumbago, the inflammation extending to the eacroiliac synchondroses. The pain was so severe that for a fortnight movement in bed was intolerable, even to the extent of raising the arms to the head. At the end of three weeks he could sit out of bed, and I soon endeavoured to get him to stand. At first he declared this impossible, but, seated by the side of an old. fashioned four-poster bedstead, I got him to grasp one of the posts, and then raising his other hand grasping. it a little higher, and gradually progressing each hand higher than the other, at last got him into the erect posi. tion, at which he was greatly surprised. I then suggested he might, with assistance from his wife and myself, walk a few steps. This he at first ridiculed, bat, nothing daunted, I encouraged him to walk across the room. This being accomplished, he walked back leaning on my arm and using a walking-stick. I shall never forget his surprise; at first he thought I was cruel to suggest his making the effort. There could not possibly be any motive in his reluctance, but evidently his will power was. so seriously deteriorated by long inaction that nothing buta stronger will than his own could have urged him to make the effort. The late Sir Benjamin Brodie waspeculiarly successtul in inducing by moral suasion and determined will young hysterical persons to make a successful effort to leave the wall against which he or she was placed and walk to him, thus overcoming the weak nerve power by a stronger influence. Mental impressions have much to do with recovery after illness, and it is frequently more difficult to induce a patient to get out of bed after an attack of fever or other debili. tating illness than to persuade him to go to bed at the commencement. The treatment of some forms of chronicaterine disease is particularly difficult on account of the tendency to yield to mental lassitude and ennui. Of course, displacement and actual disease must be taken fally into consideration.

\section{EUCALYPTUS OIL POISONING.} BY

W. E. FOGGIE, M.A., M.D.,

PHYSICIAN FOR DISEASES OF THE SKIN, DUNDEE ROYAL INFIRMARY ; LECTURER, DISEASES OF THE SKIN, ST. ANDREWS UNIVERSITY.

CASRS of poisoning by oil of eucalyptus are so infrequentthat any individual experience seems worthy of record. The case in question is as follows:

A boy of 6, who had occssionally been in the habit of getting a drop or two of eucalyptus oil on sugar, was given by mistake a teaspoonful of the same. This was about 6 o'clock one evening. About 8 he had his usual light supper, and within two hours thereafter abdominal pain and severe vomiting set in. The vomiting continued without cessation of any length and diarrhoea soon became marked. By 11 o'clock the boy became drowsy, and when he was seen about this time he was semi-comatose. He was pale and collapsed, with a small but not very quick pulse. The muscles generally were flaccid. The pupils were medium in size and equal. The conjunctival reflex was not quite abolished. The tendon reflexes were present and were not exaggerated. There was no congh and the breathing was shallow. He could be roused by very vigorous slapping of the fac $\theta$, but each time he looked dazed. Every time he was wo water, which consisted of mucus and watery material, had a matter, which consisted of mucus and watery material, had a strong smell of eucalyptus oil. After two or three hours of external stimulation very much along the lines usually adopted for opium poisoning, the heavy comatose condition appeared to pass off, and the child was allowed to sleep. He slept well and next morning, beyond being a little tired, was quite himself again. The bresth had a smell of eucalyptus oil for three days. There was never any irritation of the urinary tract. In brief, the poison showed itself by gastro-intestinal irritation and cerebral paresis. 
Eucalyptus oil, as used within its usual dose limits of $\frac{1}{2}$ to 3 minims, seems never to give rise to any toxic symptoms, but a remedy such as this, which has almost become a household stand-by for catarrh and the like, bas, in not a few cases, been taken by mistake in larger doses, and in some cases with poisonous effect. The number of such cases is as yet hut small (in fact scarcely over a dozen) and their record is naturally fragmentary, as all notes of poisoning are apt to be when the necessity of therapeutic measures must perforce prevent detailed stady of the resulting clinical phenomena. In these cases of eucalyptus poisoning the symptoms have varied greatly according to the amount of oil taken, and apparently also according to the idiosyncrasies of the patient. Incidentally it may be mentioned that Davies ${ }^{18} \mathrm{knew}$ a patient who fainted even with the smell of it.

In general, toxic symptoms have been noted after doses of 1 drachm or more, but $H$. S. Taylor ${ }^{11}$ speaks of a patient who felt a little giddiness and confusion after $\frac{1}{2}$ drachm. Most of the cases, however, developed marked toxic symptoms after doses of $1 \mathrm{drachm}$ or more, as in those of Taylor, ${ }^{11}$ Benham, ${ }^{12}$ the two of Atkinson, ${ }^{18}$ a case of Allan's, ${ }^{20}$ one case of Kirkness, ${ }^{19}$ and the above case. In other cases the dose of eucalyptus oil taken was 2 drachms, as in that of $0 r{ }^{16} 3$ drachms or even 6 drachms, as in the cases of Benjamin 14 and Myott. ${ }^{15}$

With such different dosage the time of onset of toxic symptoms has naturally varied greatly-from ten minutes in one case to one or two hours in another. In like manner the kind of symptoms and the order of their development have shown differences. Vomiting was gene. rally the first sign-in the case reported by Kunkel ${ }^{9}$ it was the only one-and it was frequently followed by abdominal pain and diarrhoea. In most of the cases, whether preceded by gastro-intestinal irritation or not, unconsciousness, varying in degree from mere drowsiness to coma, supervened.

In some the first symptom noticed was a giddiness, as in the cases of Kirkness, ${ }^{19}$ Sheaf, ${ }^{8}$ and Taylor. ${ }^{11}$ In all but the slightest cases further effects manifested them. selves in pallor, quick pulse, and general collapse, as well as frequently respiratory disturbance. No after-effects were noted beyond the temporary odour of the breath.

In most recovery with or without medical aid was quick. Generally the early vomiting removed a-large amount of the poison, and in the cases where only cerebral symptoms were present the use of an emetio led to a speody recovery. Hence an emetic, if required, and afterwards stimulant treatment, seemed in almost all the cases to give the necessary relief. The duration of the toxic symptoms in the cases recovering varied from an hour or two on an average up to ten hours in a case recorded by Benjamin, ${ }^{14}$ where a boy ill with remittent fever had got by mistake 6 drachms.

Nevinny ${ }^{6}$ in 1898 mentioned that a fatal result had not yet been observed, bat since then several have been put on record. In one reported by Lewin, ${ }^{b}$ a boy of 10 , after taking 15 grams, suffered from vomiting, pallor of the lips, rapid weak pulse, sighing respiration, and air hunger, and died in fifteen minuteg. At the post-mortem examination, blood was found in the plearal cervity. In a case of Myott's, ${ }^{15}$ a man of 34, after taking 4 drachms becsmo soon dazed and later unconscious. The pulse becsme quick and the breathing laboured. The physical signs pointed to congestion throughout both lungs. He rallied a little, bat died within forty hours after taking the oil. The post-mortem examination showed inter alia reddening of the trachea and bronchi. Nealo also reports a fatal case.

The explanation of these toxic cases has not so far been satisfactory. Schalz ${ }^{1}$ says that pure encalyptus oil is very slightly active, and that 10 grams produces no effect, while Cathbert Hall ${ }^{10}$ considers that encalyptol-the chief constituent-has probably very little toxic result. Manquat ${ }^{8}$ quotes the experiences of Bouveret and Peschade with the subcutaneous injection of encalyptol in liquid vaseline, where the patients sometimes felt a heat in the abdomen, and at other times showed symptoms of cerebral phenomena of a more or less uncomfortable nature.

Siegen, as Manquat mentions, noted with a dose of $3 \frac{1}{2}$ grams headache and mental prostration. The other phenomena are like those produced by turpentine-coma, weakness of reflexes and of the respiration, lowering of the blood pressure and temperatare, and in fatal dose respiratory paralysis. Kunkel, ${ }^{9}$ in discussing his case, considers it may have been caused by another kind of encalyptus oil, or else that it might be due to an adulteration.

REFERENCES.

1 H. Bchulz, Das Eucalyptusöl, Bonn, 1881. ${ }^{2}$ F. J. Owen, Austral. Med. Journ., Melbourne, 1885, N.S. vii, 394-7. ${ }^{3}$ E. Sheaf, BRimist MEDICAI JoURNAL, 1888, i, 849. A. Neale, Australas. Med. Gaz. Bydney, 1893, xi1, 115. L. Lewin, Lehrbuch der Toxikologie, 2te Aun.

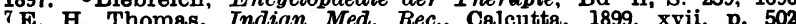
8. H. Thomas, Indian Med. Rec., Calcutta, 1899, Xvil, $^{\mathrm{D} .} 502$ 9 A. J. Kunkel, Handbuch der Toxikologie, 1901. $10 \mathrm{C}$. Héll, On Aucalyptunkel, Handbuch der Toxikologie, 11 191. 10. Hail, On Eucalyptus Oils, M.D. Thesis, Sydney, 1904. 11 H. 8. Taylor, Lancet, London, 1905 , ii, p. 963. 12 F. L. Benham, Lancet. London, 1905, ii p. 1894. 13 H. R. Davies, Lancet, London, 1906, i, 403. 14 J. Benjamin Indian Lancet, Calcutta, 1906, Xxvii, 720, also Lancet, is London, 1906 BRITISH MEDICAL JoURNAL, i. 1906, p. 558 . 16 J. Orr, ibid., 1906, p. 1085 . 17 Bchroeder. Atrztl. 8achverst. Z tg., Berlin, 1908, xiv, 153. 18 T. R. Atkinson, BRITISH MEDICAI JoURNAI, December 12th, $1909.19 \mathrm{~W}$. R. Kirkness, ibid., January 29th, 1910. ${ }^{20}$ J. Allan, ibid., March 5th, 1910.

\section{THE CURATIVE EFFECT OF SALVARSAN} (“606") IN CASES OF FRAMBOASIA.

By HENRY ALSTON, M.B., GOVERNMENT MEDICAL OFFICER, TRINIDAD.

THE following experiments were carried out at the St. Augustine Yaws. Hospital, Trinidad, from January 4th onwards. On that day Dr. Rost, the surgeon of the German cruiser Freya, who had some tubes of "606" which had been given to him at Kiel, at my reguest kindly injected five cases of yaws, three adults and two children. Dr. Rost used 0.6 gram ( 9 grains) in an emulsion with 5 to $6 \mathrm{c.cm}$. of sterilized olive oil for adults. The injection was made deeply into the muscle of the buttock. In twenty-four hours a marked improvement was noticeable, the yaws tubercles drying up from the periphery, so that whitish circles appeared to be surrounding them.

The improvement continued, and on January 8th I decided to try an experiment. I had read that in the case of an injected syphilitic mother and suckling the baby was cured by suckling the mother; and I was also aware of Professor Ehrlich's view that "606" created an antibody by rapidly destroying spirochaetes. I therefore put a cantharides blister on two of the cases being cured by the " 606 " treatment, and injected the serum from the blister into several cases of yaws, the adult dose being $16 \mathrm{c.cm}$. To my astonishment, the serum acted as rapialy as "606." In some cases improvement was noticed in sixteen hours after injection. On January 11th, at my request, Dr. Rost injected thirteen more cases of yaws with "606," and the same rapid improvement was noticeablo - in some cases as early as sixteen hours after. I applied fly blisters to some of these cases and used the serum for more experiments. In every case injected with serum I got a rapid improvement.

I ought to inject the serum cases every seven or ten days; but I am leaving them alone to see how long the improvement after a single dose of serum will last.

On January 17th the Yaws Hospital was visited by the Acting Surgeon-General, Dr. J. W. Eakkin, Dr. Rost, and two of my confrères, who saw all the cases under treatment both with " 606 " and seram, and who also saw the detailed account in my book.

I believe that this is the first instance known of a drug producing an antitoxic serum with curative properties, and the effect, in a boy, of injecting 2 drachms and 20 minims of a serum that had not been hyper-immunized, was very astonishing.

But a greater astonishment was to come. I pat a cantharides blister on two cases that were being cured by the serum from a " 606 " case, and in both an improvement was noticeable in twenty-four hours. Being boys, each received $8 \mathrm{cccm}$. of serum. Whether the effect is due to the drug or to an antitoxin, the dilution is very great in what I call the secondary serum cases.

It occurred to me that the results I obtained with serum would be explained if the failure of a cure by Nature was due to the absence of complement in the blood of yaws patients. I argued that it was possible that the antibody 